\title{
AVALIAÇÃo do INTERESSE PRÉVIO DE COMERCIANTES DA CIDADE DE JANUÁRIA - MG, PELA IMPLANTAÇÃO DA COLETA SELETIVA
}

\author{
Nathylla Bianca Costa e Nunes ${ }^{1}$ \\ Rodrigo Nogueira Martins ${ }^{2}$ \\ Juciara Oliveira Lopes ${ }^{3}$ \\ José Ângeles Moreira de Oliveira ${ }^{4}$ \\ Danilo Pereira Ribeiro 5
}

Resumo - Este trabalho objetivou avaliar o interesse de comerciantes da cidade de Januária - MG sobre implantação e participação na coleta seletiva dos resíduos sólidos gerados em seus estabelecimentos. Para isso, foram aplicados questionários a uma amostra do comércio local. A pesquisa foi realizada na maior Avenida da cidade com predomínio de comércios, a Av. Cônego Ramiro Leite, no centro de Januária/MG, onde foram realizadas 3 entrevistas por quadra, com total de 42 amostras. A maioria dos comércios entrevistados dispõe seus resíduos para coleta de lixo sem se preocupar com a reciclagem. Mais da metade dos entrevistados não sabem a diferença de aterro para lixão o que desfavorece a sensibilização para solucionar o problema ambiental. Menos da metade dos entrevistados sabe a frequência correta de coleta na avenida. A maioria se mostrou interessado na implantação da coleta seletiva e afirmou que iria aderir e as frequências de coleta mais sugeridas foram de 4 a 6 dias por semana. $O$ principal resíduo reciclável gerado é o papel que se estraga muito fácil, caso não seja adequadamente separado.

Palavras-chave: Resíduos sólidos; Aterro sanitário; reciclagem.

\footnotetext{
${ }^{1}$ Departamento de Engenharia Agrícola e Ambiental/Instituto Federal do Norte de Minas Gerais - IFNMG Campus Januária, Brasil. E-mail: nathylla@yahoo.com.br.

2 Departamento de Engenharia Agrícola e Ambiental/Instituto Federal do Norte de Minas Gerais - IFNMG Campus Januária, Brasil. E-mail: rodrigonmartins@hotmail.com.

${ }^{3}$ Departamento de Engenharia Agrícola e Ambiental/Instituto Federal do Norte de Minas Gerais - IFNMG Campus Januária, Brasil. E-mail: juciaraoliveiralopes@yahoo.com.br.

${ }^{4}$ Departamento de Engenharia Agrícola e Ambiental/Instituto Federal do Norte de Minas Gerais - IFNMG Campus Januária, Brasil. E-mail: j.ngeles@yahoo.com.

${ }^{5}$ Doutor em Engenharia Agrícola/Departamento de Engenharia Agrícola e Ambiental/Instituto Federal do Norte de Minas Gerais - IFNMG Campus Januária, Brasil. E-mail: danilo.ribeiro@ifnmg.edu.br.
} 